\title{
Record of the goblin shark Mitsukurina owstoni (Chondrichthyes: Lamniformes: Mitsukurinidae) from the south-western Atlantic
}

\author{
GETULIO RINCON ${ }^{1}$, TEODORO VASKE JÚNIOR ${ }^{2}$ AND OTTO B.F. GADIG ${ }^{2}$ \\ ${ }^{1}$ Conepe-Conselho Nacional de Pesca e Aquicultura, Setor Hoteleiro Sul, Quadra 6, Conj. A, Bloco E, Edifício Brasil 21, Salas 10-13, \\ CEP 70322-915, Brasília, Distrito Federal, Brazil, ${ }^{2}$ UNESP, Campus Experimental do Litoral Paulista, Praça Infante Dom Henrique \\ s/n, CEP 11330-900, São Vicente, São Paulo, Brazil
}

\begin{abstract}
This paper reports the first well-documented specimen of the goblin shark, Mitsukurina owstoni in the south-western Atlantic, based on a mature male measuring $3152 \mathrm{~mm}$ total length, caught on 27 November 2008 off the Rio de Janeiro coast, southeast Brazil.
\end{abstract}

Keywords: goblin shark, Mitsukurina owstoni, occurrence, south-western Atlantic

Submitted 26 June 2011; accepted 25 July 2011

\section{INTRDDUCTION}

The goblin shark, Mitsukurina owstoni (Jordan, 1898) is the single representative of the family Mitsukurinidae, order Lamniformes (mackerel sharks), distributed worldwide in deep waters down to at least $1300 \mathrm{~m}$ and occasionally reaching the shallow upper slopes of submarine canyons. It is one of the most bizarre large sharks known, attaining about $4100 \mathrm{~mm}$ total length, and characterized by its long and well depressed paddle-like snout, extremely narrow and unserrated lanceolate and acute teeth, and unusual pinkish-grey colour in live or freshly-dead specimens (Kukuev, 1982; Compagno, 2001). The species was described based on one $1070 \mathrm{~mm}$ total length (TL) immature male from Yokohama, Japan and since then about 230 specimens have been recorded worldwide in the literature, mostly from Japanese waters, representing at least 185 specimens (summarized by Yano et al., 2007) or about $80.4 \%$ of all known specimens since its original description.

Non-Japanese reports comprise a few individuals caught in the western Pacific-Taiwan (Lee \& Shao, 2010), Australia (Glover, 1976; Stevens \& Paxton, 1985; Last \& Stevens, 2009) and New Zealand (Davison \& Van Berkel, 1985; Stewart \& Clark, 1988; Duffy, 1997); eastern Pacific-southern California (Ugoretz \& Siegel, 1999); western Indian Oceanoff South Africa (Piotrovskiy \& Prut'ko, 1980); eastern Atlantic-Portugal, France, Guinea, (Bragança, 1904; Quéro, 1972; Quéro et al., 1976; Cadenat \& Blache, 1981), western Cape, off South Africa (Bass et al., 1975); western North Atlantic-Corner and New England Rising Seamounts (Kukuev, 1982), Gulf of Mexico (Parson et al., 2002),
Colombia (Grijalba-Bendeck \& Acevedo, 2009), French Guiana (Uyeno \& Sasaki, 1983) and northern Brazil (Holanda \& Asano-Filho, 2008).

Although widely distributed, some available biological and distribution data are controversial. For example, the first record from the western North Atlantic, in fact was not that published by Uyeno et al. (1983), but from Kukuev (1982) who reported nine specimens collected between 1976 and 1978 at Corner Mountains and New England Seamounts. One of these sharks measured $4100 \mathrm{~mm}$ TL (sex not given), representing the largest specimen effectively measured, despite the $3840 \mathrm{~mm}$ TL adult male recorded by Stevens \& Paxton (1985) reputed to be the largest. Larger individuals would be expected considering the general growth pattern in sharks, in which the females usually attain larger sizes than males (Compagno, 2001). The large female recorded by Parsons et al. (2002) was estimated (based on photographs) between 5400 and $6170 \mathrm{~mm}$ TL.

Previous Brazilian records were made in the western North Atlantic area. The search for new deep-water fishery sources by the Brazilian Environmental Agency (IBAMA) on the north coast (States of Amapá and Pará) between 2002 and 2004, resulted in the capture of six specimens which were discharged at sea without further analysis, except one $1050 \mathrm{~mm}$ TL immature female deposited at the Museu Oceanográfico do Vale do Itajaí (MOVI 37411). Only photographic records of these specimens were saved and provide the positive species identification. Soto \& Mincarone (2004) briefly list its institutional deposit. However, Holanda \& Asano-Filho (2008) in a report on these above mentioned north Brazilian specimens do not present any biological information, sex, size or even collection number of this specimen. Therefore, these records in Brazilian waters are confusing, split in different publications and lack additional information on the reported material. 
The expected western South Atlantic record of M. owstoni started with rumours of its capture by the monkfish (Lophius gastrophysus Miranda Ribeiro, 1915) fishery between 2000 and 2003 in southern Brazil off the Rio Grande do Sul coast. One photograph of a small goblin shark was credited to this fishery, but no confirmation of capture area, depth, boat or specimens were ever provided.

In the present study the occurrence of goblin shark in the western South Atlantic is positively reported based on a $3152 \mathrm{~mm}$ TL and $99 \mathrm{~kg}$ total weight (TW) mature male, providing biological data from this large and previously unknown distribution area for this species.

\section{MATERIALS AND METHODS}

The specimen was caught by the chartered Spanish $38 \mathrm{~m}$ long fishery vessel 'Albamar' with an otter trawl for deep-water scarlet shrimps, genus Aristaeopsis, on 27 November 2008 between 700 and $1000 \mathrm{~m}$ depth off the State of Rio de Janeiro, about $23^{\circ} 52.087^{\prime} \mathrm{S}-23^{\circ} 51.402^{\prime} \mathrm{S}$ and $41^{\circ} 52.708^{\prime} \mathrm{W}-$ $42^{\circ} 05.236^{\prime} \mathrm{W}$, frozen on-board and transferred to the freezer at the São Paulo State University (UNESP, CLP, São Vicente, São Paulo) where it was frozen for about three months before analysis.

In the laboratory, the specimen was weighted (total weight (TW)) and measured for TL. All measurements, body terminology and general biological data were taken according to the methods of Stevens \& Paxton (1985) and Yano et al. (2007). Maturity was determined by the presence of semen in the seminal vesicle and claspers calcification. Stomach and intestine contents were collected and preserved in formalin (4\%) and alcohol solutions (96\%), respectively. The reproductive system was preserved in formalin (4\%) for posterior analysis. The tooth count and terminology were modified from Shimada \& Seigel (2005), where: S, symphysial tooth; A, anterior; I, intermediate; L, lateral; and P, posterior.

After biological and morphological analysis the specimen was donated to the Museu de Pesca de Santos, São Paulo (uncatalogued), where it was prepared by a taxidermist and displayed for public appreciation.

\section{RESULTS}

Proportional dimensions of the $99 \mathrm{~kg}$ TW and $3152 \mathrm{~mm}$ TL mature male goblin shark (Figure 1) are presented in Table 1 and expressed as percentage of the TL (in $\mathrm{mm}$ ). General morphology is similar to most previous described similarsized large specimens. Trunk robust, compressed and soft even in the large frozen specimen (Figure 1A). No lateral caudal keel, precaudal pit or abdominal grooves were observed. Trunk length (from 5 th gill slit to upper caudal lobe origin) $40.0 \%$ of TL. Head length shorter than trunk length and slightly less than $1 / 3$ of TL. Eye relatively small, its diameter about $0.92 \%$ of TL, more than 16 times in snout length. Large and angular mouth (not protused when caught and during the frozen process), its width $6.82 \%$ of TL and three times the head length. First dorsal fin origin slightly posterior to inner (distal) tip of the pectoral fin, similar in height to second and both smaller than anal, remarkably considering the overall length. Distance between dorsal fins similar to head length and about three times the second dorsal to upper caudal lobe distance. Pectoral to pelvic distance $18.21 \%$ of TL. Anal origin close to pelvic fin insertion, separated by a distance correspondent to $4.09 \%$ of TL, or about four times the distance between dorsal fins. Upper caudal lobe well developed, $35.88 \%$ of TL. Coloration dark-pink shortly after its capture and during the first weeks of freezing, but the pink was gradually replaced by a greyish-brown tone.

The tooth count is right upper jaw $3(\mathrm{~A})-\mathrm{O}(\mathrm{I})-1 \mathrm{O}(\mathrm{L})-$ $11(\mathrm{P})=24$; left upper jaw $3(\mathrm{~A})-\mathrm{O}(\mathrm{I})-10(\mathrm{~L})-12(\mathrm{P})=25$; right lower jaw $1(\mathrm{~S})-3(\mathrm{~A})-\mathrm{O}(\mathrm{I})-9(\mathrm{~L})-12(\mathrm{P})=25$; left lower jaw $1(\mathrm{~S})-3(\mathrm{~A})-\mathrm{O}(\mathrm{I})-9(\mathrm{~L})-1 \mathrm{O}(\mathrm{P})=23$. Tooth similar in both jaws, slender, smooth-edged, acute and lanceolate, lacking lateral basal cusps (Figure $1 \mathrm{~B}$ ). Upper jaw with a gap between 3 rd and 4 th tooth rows without intermediate small
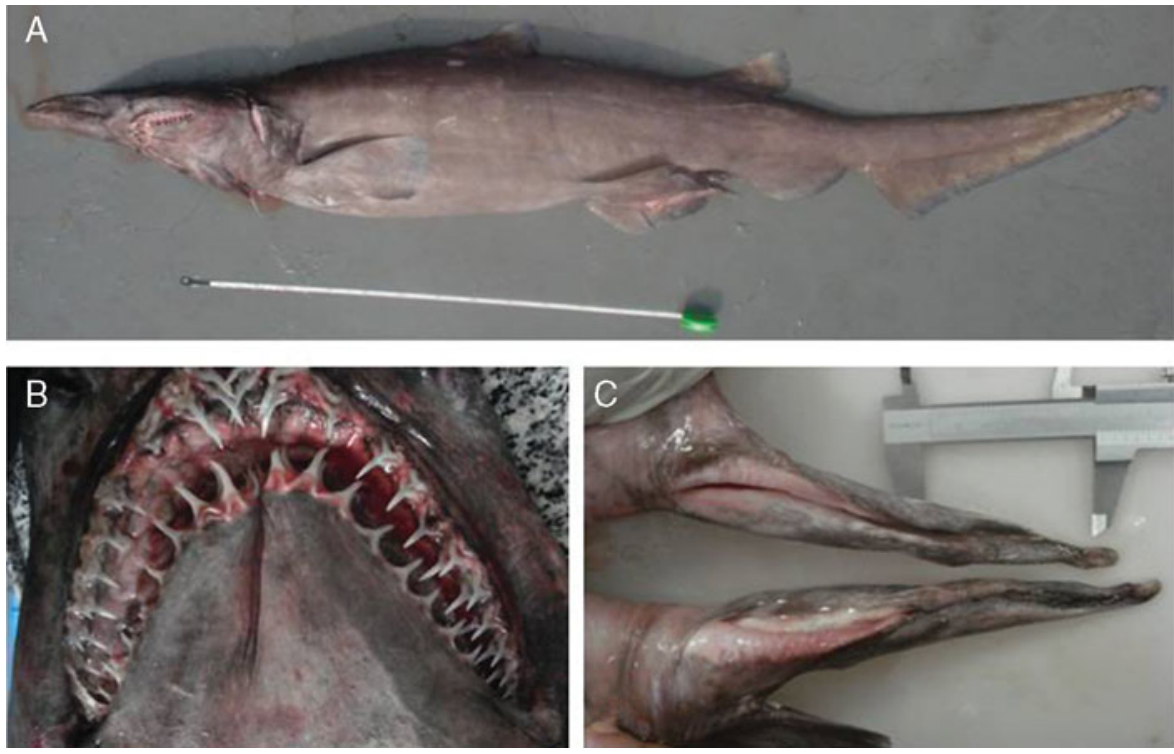

Fig. 1. (A) Mitsukurina owstoni, $3152 \mathrm{~mm}$ total length mature male, from Rio de Janeiro, Brazil; (B) showing ventral view of mouth and teeth; and (C) well developed calcified claspers. 
Table 1. Proportional dimensions of $3152 \mathrm{~mm}$ total length mature male Mitsukurina owstoni expressed as percentages of total length.

\begin{tabular}{|c|c|c|c|c|c|}
\hline & $\mathbf{m m}$ & $\%$ & & $\mathbf{m m}$ & $\%$ \\
\hline TOTAL LENGTH & 3125 & 100 & & & \\
\hline SNOUT TIP TO: & & & ANAL FIN: & & \\
\hline Outer nostrils & 320 & 10.15 & Overall length & 379 & 11.92 \\
\hline Eye & 388 & 12.30 & Length base & 335 & 10.62 \\
\hline Spiracle & 516 & 16.37 & Length posterior margin & 23 & 0.72 \\
\hline Mouth & 508 & 16.11 & Height & 171 & 5.42 \\
\hline 5 th gill opening & 760 & 24.11 & PECTORAL FIN: & & \\
\hline Pectoral origin & 772 & 24.49 & Length base & 173 & 5.48 \\
\hline Pelvic origin & 1494 & $47 \cdot 39$ & Length anterior margin & 324 & 10.27 \\
\hline 1st dorsal fin origin & 1128 & 35.78 & Length posterior margin & 181 & 5.74 \\
\hline 2nd dorsal fin origin & 1843 & 58.47 & PELVIC FIN: & & \\
\hline Anal fin origin & 1908 & 60.53 & Overall length & 378 & 11.99 \\
\hline \multirow[t]{2}{*}{ Upper caudal origin } & 2021 & 64.11 & Length anterior margin & 231 & $7 \cdot 32$ \\
\hline & & & Length clasper from cloaca & 175 & 5.55 \\
\hline DISTANCE BETWEEN FINS: & & & Length clasper from pelvic axis & 142 & 4.50 \\
\hline 1st and 2 nd dorsal fins & 526 & 16.68 & CAUDAL FIN: & & \\
\hline 2nd dorsal and upper caudal & 174 & 5.52 & Length upper lobe & 1131 & 35.88 \\
\hline Pectoral and pelvic & 574 & 18.21 & $\begin{array}{l}\text { Length lower lobe } \\
\text { OTHER MEASUREMENTS: }\end{array}$ & 291 & 9.23 \\
\hline 1st DORSAL FIN: & & & Internasal distance & 126 & 3.99 \\
\hline Overall length & 286 & 9.07 & Mouth width & 215 & 6.82 \\
\hline Length base & 183 & 5.80 & Mouth length & 182 & 5.77 \\
\hline Length posterior margin & 112 & 3.55 & Upper labial furrow & 10 & 0.31 \\
\hline \multirow[t]{2}{*}{ Height } & 126 & 3.99 & Lower labial furrow & 35 & 1.11 \\
\hline & & & 1st gill opening length & 125 & 3.96 \\
\hline 2nd DORSAL FIN: & & & 3 rd gill opening length & 109 & 3.45 \\
\hline Overall length & 251 & 7.96 & $5^{\text {th }}$ gill opening length & 84 & 2.66 \\
\hline Length base & 189 & 5.99 & Eye horizontal diameter & 29 & 0.92 \\
\hline Length posterior margin & 111 & 3.52 & Eye vertical diameter & 23 & 0.65 \\
\hline Height & 125 & 3.96 & Interorbital width & 192 & 6.09 \\
\hline
\end{tabular}

tooth. For both jaws, anterior and lateral teeth are much larger than the posterior, with erect cusp, decreases in size towards mouth corner. Symphysial tooth present only in the lower jaw, smaller than and morphologically similar to anterior and lateral teeth. Posterior are much smaller, morphologically distinct with a less pronounced cusp, almost blunt near the mouth corner.

The shark herein examined is an adult male, since the claspers were rigid, calcified, fully developed, measuring $175 \mathrm{~mm}$ from pelvic fin inner margin (representing 5.55\% TLFigure ${ }_{1} \mathrm{C}$ ) and semen in the seminal vesicle. The epididymis measured $\sim 304 \mathrm{~mm}$ long and $\sim 4.5$ to $5.6 \mathrm{~mm}$ wide and highly convoluted. The testes measured $113 \mathrm{~mm}$ long and $34 \mathrm{~mm}$ wide (left) and $152 \mathrm{~mm}$ long and $36 \mathrm{~mm}$ wide (right). The visceral organs were dorsally covered by the long epigonal organs, one on each side of vertebral column, extending to the cloacal region. Both seminal vesicles measured $402 \mathrm{~mm}$ long and $295 \mathrm{~mm}$ wide, showed semen constantly secreted by the urogenital papilla as dissection proceeded. The ventral wall of the belly was $50 \mathrm{~mm}$ thick and the organs were latero-ventrally protected by both liver lobes. Only the distal stomach and spleen were not ventrally covered by liver. The liver is long, weighted $12.43 \mathrm{~kg}$ (12.55\% of the TW), extending from the heart to rectum in two lobes ( $935 \mathrm{~mm}$ left lobe). The stomach measured $670 \mathrm{~mm}$ long, and it was empty. The duodenum measured $390 \mathrm{~mm}$ long and the spiral valve intestine was $650 \mathrm{~mm}$ long with 19 lamellae (turns). The spiral valve was washed and examined under stereoscopic microscope, but no contents were found.

\section{DISCUSSION AND CDNCLUSIDN}

Most morphometrics and morphological data herein observed agree with previous species descriptions concerning large individuals with similar size (Stevens \& Paxton, 1985; Ugoretz \& Seigel, 1999). Minor differences are attributed to distinct protocols and/or usual difficulties in manipulation of a large specimen. Some morphological differences between specimens from several regions are regarded as ontogenetic variations (Bean, 1905; Stevens \& Paxton, 1985; Yano et al., 2007). But Hussakof (1909, as Scapanorhynchus jordani) noted distinct snout shape (broad and acute) in two small females of similar size (1160 and $1330 \mathrm{~mm} \mathrm{TL}$ ). Kukuev (1982), studying large specimens between 2000 and $4100 \mathrm{~mm}$ TL from the western North Atlantic, noted some morphological differences between these specimens and the $1070 \mathrm{~mm}$ TL holotype from Japan (Jordan, 1898); remarkably the posterior first dorsal fin position (anterior in the Jordan's holotype) and the shorter upper caudal lobe (longer in the original description), suggest that such differences are due to ontogenetic reasons. In fact, most general descriptions and images of Mitsukurina available in the literature (including the present specimens), and even the small ones, have the first dorsal fin origin more posterior in relation to pectoral and upper caudal lobe relatively shorter if compared to the illustration provided in Jordan (1898). In the holotype illustration the origin of first dorsal is over the pectoral insertion, and in most specimens recorded the first dorsal fin origin is over the pectoral inner margin, or over its tip or even posterior. Unfortunately, the holotype is lost, so comparisons 
cannot be made. Stevens \& Paxton (1985) comparing morphometric data from several specimens in the literature stated that small specimens have a shorter trunk length and longer head length, and in larger sharks the head decreases in length and the larger trunk is due to the increases of fin bases and between fins.

All teeth rows were counted for the Brazilian specimen and the data are similar to values for this species. Pertaining to the dental formulae, the posterior diminute teeth rows are usually regarded as very difficult to count, resulting in some differences. Duffy (1997) informs that the small size and flattened crown morphology of the lateral tooth (here regarded as posterior) made counting difficult, consequently the counts for three New Zealand specimens were incomplete for posterior teeth. Tooth arrangement and morphology also are variable among different individuals in part due to different tooth terminology. Brazilian specimens and most recorded sharks lack basal cusps in the tooth base, but the basal cusps were recorded in lateral teeth of some individuals (Stevens \& Paxton, 1985; Duffy, 1997; Ugoretz \& Seigel, 1999). The data of Mitsukurina from around the world do not permit to conclude, at the moment, if such tooth counts, arrangement and morphology heterodonty are related to sizeclasses, sex or geographical variation. Unfortunately some of these above mentioned published studies, although presenting consistent data, do not show any image of jaws and/or teeth.

There are a few reports on mature Mitsukurina but which lack data on reproductive biology, size at first maturity, litters and other important biological parameters. The shark herein examined is one of the few mature males known to date. The larger Japanese male studied by Yano et al. (2007), a $2085 \mathrm{~mm}$ TL immature, had claspers measuring $100 \mathrm{~mm}$ (2.4\% of TL) described as soft and uncalcified. Stevens \& Paxton (1985) examined a large adult male (3840 mm TL) and the claspers represented $3.9 \%$ of the TL. The smallest known mature male measured $2620 \mathrm{~mm}$ TL (Fowler, 1941). Additional mature males include individuals of $3220 \mathrm{~mm}$ (Piotrovskiy \& Prut'ko, 1980), 3500 mm (Masay et al., 1973) and $3730 \mathrm{~mm}$ (Kobayashi et al., 1982).

Although previously recorded without any specimen's description or biological information (Holanda \& AsanoFilho, 2008), the presence of the goblin shark in Brazilian waters is confirmed based on preserved specimens from the States of Amapá and currently in Rio de Janeiro and this present report suggests a continuous distribution of the species in deep waters (probably benthopelagic habits) along all Brazilian coasts, confirming its presence also in the western South Atlantic.

\section{ACKNDWLEDGEMENTS}

The authors are grateful to the crew of the Spanish fishery vessel 'Albamar' for donation, store and transportation of the shark. To Nelson Dreux (Instituto de Pesca de Santos, São Paulo), Aline F. Pasquino, Camila M.H. Santos, Debora Balbino and Fernanda Rocha, (Laboratório de Pesquisa de Elasmobrânquios, UNESP, Campus Experimental do Litoral Paulista, São Paulo) and Ana Rita Onodera Palmeira (Universidade Federal da Paraíba, João Pessoa) for helping in the specimen dissection.

\section{REFERENCES}

Bass A.J., D'Aubrey J.D. and Kistnasamy N. (1975) Sharks of the east coast of southern Africa. IV. The families Odontaspididae, Scapanorhynchidae, Isuridae, Cetorhinidae, Alopiidae, Orectolobidae and Rhiniodontidae. Investigational Report of the Oceanographic Research Institute 39, 1-102.

Bean B.A. (1905) Notes on an adult goblin shark (Mitsukurina owstoni) of Japan. Proceedings of the United States National Museum 28, 815-818.

Bragança D.C. (1904) Ichtiologia. II. Esqualos obtidos nas costas de Portugal durante as campanhas de 1869-1903. Resultados das Investigações Scientificas feitas à Bordo do Yacht Amélia, Lisboa, $107 \mathrm{pp}$.

Cadenat J. and Blache J. (1981) Requins de Méditerranée et d'Atlantique. Paris: Office de la Recherche Scientifique et Technique d'Outre-Mer.

Compagno L.J.V. (2001) Sharks of the world. An annotated and illustrated catalogue of shark species known to date. Bullhead, mackerel and carpet sharks (Heterodontiformes, Lamniformes and Orectolobiformes). FAO Species Catalogue for Fishery Purposes 1, $1-269$.

Davison V. and Van Berkel J.G.J.M. (1985) Further additions to the records of marine fishes from Kaikoura. Mauri Ora 12, 147-150.

Duffy C.A.J. (1997) Further records of the goblin shark, Mitsukurina owstoni (Lamniformes: Mitsukurinidae), from New Zealand. New Zealand Journal of Zoology 24, 167-171.

Fowler H.W. (1941) Contributions to the biology of Philippine Archipelago and adjacent regions. Bulletin of the United States National Museum 13, 1-879.

Glover C.J.M. (1976) The goblin shark, Scapanorhynchus owstoni (Jordan, 1898): confirmation of the first Australian record. South Australian Naturalist 50, 59-62.

Grijalba-Bendeck M. and Acevedo K. (2009) Mitsukurina owstoni Jordan (Chondrichthyes: Mitsukurinidae) primer registro para El Caribe colombiano. Boletin de Investigaciones Marinas y Costeras 38, $211-215$.

Holanda F.C.A.F. and Asano-Filho M. (2008) Registro de ocorrência do tubarão duende Mitsukurina owstoni (Jordan, 1898) (Lamniformes, Mitsukurinidae) na costa Norte do Brasil. Arquivos de Ciências do Mar 41, $101-104$.

Hussakof L. (1909) A new goblin shark, Scapanorhynchus jordani, from Japan. Bulletin of the American Museum of Natural History 26, 257-262.

Jordan D.S. (1898) Description of a species of fish (Mitsukurina owstoni) from Japan, the type of a distinct family of lamnoid sharks. Proceedings of the California Academy of Sciences (Zoology) 1, 199-202.

Kobayashi H., Yamaguchi Y., Nonoda T., Izawa K. and Ban H. (1982) The sharks caught on the continental shelf and slope in Kumano Nada region along the Pacific coast of Japan. Bulletin of the Faculty of Fisheries Mie University 9, 101-123.

Kukuev E.I. (1982) Fish fauna of the Corner Mountains and New England submarine ridge in the western North Atlantic. In Parin N.V. (ed.) Poorly known fishes of the open ocean. Moscow: Institute of Oceanology Academy of Sciences of the USSR, pp. 92-109.

Last P.R. and Stevens J.D. (2009) Sharks and rays of Australia. Cambridge, MA: Harvard University Press.

Lee P.F. and Shao K.T. (2010) Two new records of lamniform shark from the waters adjacent to Taiwan. Journal of the Fisheries Society of Taiwan 36, 303-311.

Masay H., Sato Y. and Aoki M. (1973) The brain of Mitsukurina owstoni. Journal für Hirnforschung 14, 493-500. 
Miranda-Ribeiro A. (1915) Fauna Braziliense. Peixes. V. (Eleutherobranchios Aspirophoros) Physoclisti. Archivos do Museu Nacional, Rio de Janeiro 17, 2-5.

Parsons G.R., Ingram Jr. G.W. and Havard R. (2002) First record of the goblin shark Mitsukurina owstoni, Jordan (Family Mitsukurinidae) in the Gulf of Mexico. Southeastern Naturalist 1, 189-192.

Piotrovskiy A.S. and Prut'ko V.G. (1980) The occurrence of the goblin shark, Scapanorhynchus owstoni (Chondrichthyes, Scapanorhynchidae), in the Indian Ocean. Journal of Ichthyology 20, 124-125.

Quéro J.C. (1972) Capture de deux Scapanorhynchus owstoni (Jordan, 1898) (Selachii, Scapanorhynchidae) par des chalutiers de la Rochelle. Annales de la Société des Sciences Naturelles de la Charente Maritime 5, 168-170.

Quéro J.C., Verron R. and Cattin Y. (1976) Observations ichthyologiques effectuées au port de la Rochelle en 1975. Annales de la Société des Sciences Naturelles de la Charente Maritime 6, 117-190.

Shimada K. and Seigel J.A. (2005) The relationship between the tooth size and total body length in the goblin shark, Mitsukurina owstoni (Lamniformes: Mitsukurinidae). Journal of Fossil Research 38, 49-56.

Soto J.M.R and Mincarone M.M. (2004) Collections of the Museu Oceanográfico do Vale do Itajaí. I. Catalogo of Cartilaginous Fishes, Mixini, Cephalaspidomorphi, Elasmobranchii, Holocephali. Mare Magnum 2, 1-125.

Stevens J.D. and Paxton J.R. (1985) A new record of the goblin shark, Mitsukurina owstoni (Family Mitsukurinidae), from eastern
Australia. Proceedings of the Linnaean Society of New South Wales $108,37-45$.

Stewart A.L. and Clark M.R. (1988) Records of three families and four species of fish new to the New Zealand fauna. New Zealand Journal of Zoology 15, 577-583.

Ugoretz J.K. and Seigel J.A. (1999) First eastern Pacific record of the goblin shark, Mitsukurina owstoni (Lamniformes, Mitsukurinidae). California Fish and Game 85, 118-120.

Uyeno T. and Sasaki K. (1983) Mitsukurina owstoni Jordan, 1898. In Uyeno T., Matsuura K. and Fujii E. (eds) Fishes trawled off Suriname and French Guiana. Tokyo: Japan Marine Fishery Resource Research Center, p. 48.

and

Yano K., Miya M., Ayzawa M. and Noichi T. (2007) Some aspects of the biology of the goblin shark, Mitsukurina owstoni, collected from the Tokyo Submarine Canyon and adjacent waters, Japan. Ichthyological Research 54, 388-398.

Correspondence should be addressed to: O.B.F. Gadig UNESP, Campus Experimental do Litoral Paulista Praça Infante Dom Henrique s/n CEP 11330-900, São Vicente São Paulo, Brazil email: gadig@clp.unesp.br 